\title{
Evaluation of Relationship between Obsessive-compulsive Disorder and Dissociative Experiences
}

\author{
Mustafa Tatlı ${ }^{1}$, Ozlem Cetinkaya ${ }^{2}$, Fulya Maner ${ }^{3}$ \\ ${ }^{1}$ Psychiatry Clinic, Medikar Private Hospital, Karabuk, ${ }^{2}$ Psychiatry Clinic, Bakırkoy Mazhar Osman Mental Health and Neurological Diseases \\ Education and Research Hospital, Istanbul, ${ }^{3}$ Department of Child Development, Kırklareli University, Kırklareli, Turkey
}

\begin{abstract}
Objective: The aim of the study is to evaluate the relationship between obsessive-compulsive disorder (OCD) symptoms and dissociative experiences and the effect of childhood traumatic experiences on this relationship in OCD patients. Methods: Fifty consecutive OCD patients and 50 healthy controls are enrolled for this study. Sociodemographic and Clinical Data Form, Dissociative Experiences Scale (DES), Padua Inventory (PI) and Childhood Trauma Questionnaire (CTQ) are applied to participants.

Results: Average DES total score in the patient group is 20.58 and in the control group it is 4.87 . In the patient group, when we evaluate the relation strengths of DES total and subscale scores with PI total score, we found out that amnesia subscale has $r=0.361(p<0.01)$, absorption subscale has $r=0.611(p<0.01)$, depersonalization/derealization subscale has $\mathrm{r}=0.574(p<0.01)$, and DES total score has $\mathrm{r}=0.55(p<0.01)$ relation strengths with $\mathrm{Pl}$ total score. In patient group both DES total score and CTQ total score have influence on PI total score independently from each other. In addition to this, the level of the influence of DES total scores on PI total scores is, $\mathrm{R}^{2}=0.399(p<0.01)$ and the level of the influence of CTQ total scores on $\mathrm{Pl}$ total scores is $\mathrm{R}^{2}=0.343(p<0.01)$.

Conclusion: Dissociative experiences are seen more frequently in OCD patients than healthy controls. Among dissociative experiences, absorption has stronger relation with OCD symptoms. The relation between OCD and dissociation is independent from and stronger than the relation between childhood traumatic experiences and OCD.
\end{abstract}

KEY WORDS: Obsessive-compulsive disorder; Dissociation; Trauma.

\section{INTRODUCTION}

In Diagnositc and Statistical Manual of Mental Disorders fifth edition (DSM-5), dissociation is described as deterioration or separation in the integrated functions of consciousness, memory, identity, environmental perception, body representation, emotion and behavior. ${ }^{1)}$ According to community-based studies, the frequency of dissociative manifestations in the general population is estimated at $5.6-10 \%{ }^{2}{ }^{2}$ Traumatic experiences, especially childhood traumatic experiences, are the most frequently studied etiological factor for the development of disso-

Received: January 2, 2017 / Revised: April 7, 2017 Accepted: April 18, 2017

Address for correspondence: Mustafa Tatl1, MD

Psychiatry Clinic, Medikar Hastanesi, Universite mah, Şehit Ateşe Reşat Moralı Blv. No: 7, 78200 Karabuk, Turkey Tel: +90-370-415-63-78, Fax: +90-370-415-38-78

E-mail: drmustafatatli@yahoo.com

ORCID: https://orcid.org/0000-0002-9776-1951 ciation. ${ }^{3,4)}$ Also, there are plenty of studies in which it is found that, in many psychiatric disorders such as posttraumatic stress disorder, panic disorder, somatization disorders, eating disorders, borderline personality disorder and obsessive-compulsive disorder (OCD), frequency of dissociative manifestations is higher than healthy controls. ${ }^{5)}$

Studies about cognitive processes of obsessions, compulsions and dissociative experiences reported that, individuals with high tendency to obsessive thoughts or compulsive behaviors and dissociative symptoms, experience common cognitive difficulties while reconciling the pre-existent schemes about themselves and the world with new information from outside and responding to the changes in their surroundings. ${ }^{6,7)}$

Dissociative experiences are defense reactions mostly against outside traumatic experiences, while obsessions and compulsions develop in response to incitement created by anxiety-enhancing thoughts. In some way, ob-

(ㄷ) This is an Open-Access article distributed under the terms of the Creative Commons Attribution Non-Commercial License (http://creativecommons.org/licenses/by-nc/4.0) which permits unrestricted non-commercial use, distribution, and reproduction in any medium, provided the original work is properly cited. 
sessions and compulsions can be referred as defense mechanisms against internal traumas mostly caused by intolerable thoughts whereas dissociative experiences can be referred as reactions against external traumatic situations.

From the psychoanalytic perspective, there are three prominent defensive mechanisms to explain the symptoms of OCD. These are reaction-formation, isolation and undoing mechanisms. Among them, isolation means separation of certain thoughts and behaviors from the rest of the experience. In this definition, isolation refers to a defense mechanism very similar to dissociation, as in dissociation there is a separation or dissolution in the mental processes functioning in unity. ${ }^{8)}$

When we look at the studies in the literature that interpret OCD and dissociative experiences together, Lochner et al. ${ }^{9)}$ reported the prevalence of dissociative symptoms in OCD patients as $20 \%$. This study can be interpreted as the dissociative experiences in OCD patients are approximately twice as common as the general population, because in general population the prevalence of dissociative symptoms is estimated to be $5.6-10 \% .^{2)}$ In their study, Merckelbach and Wessel ${ }^{10)}$ compared 19 OCD patients with healthy controls and they reported that the Dissociative Experiences Scale (DES) scores were higher in the OCD group than in the control group. In the study conducted by Prasko et al., ${ }^{111}$ it is reported that there is no statistically significant difference in the DES scores between the OCD and the control group; however, it is concluded in the same study that there are differences between groups in terms of gender distribution which might have affected the study results. In addition to these studies, different interpretations about the relationship between OCD symptom severity and dissociative symptoms have been reported in the literature; Lochner et al.., Goff et al., ${ }^{12)}$ Belli et al., ${ }^{13)}$ and Hodgson and Rachman ${ }^{14)}$ reported that there is a relationship between dissociative experiences and OCD symptom severity in their studies. However, Rufer et al. ${ }^{15)}$ reported that dissociative experiences in OCD patients are associated with the severity of depressive symptoms, but not with obsessive-compulsive symptom severity. Similarly, Raszka et al. ${ }^{16)}$ concluded that the dissociative tendency in OCD patients was related to anxiety rather than OCD symptoms. In the studies which interpret the relations between OCD symptom types and dissociative experiences, it is reported that dis- sociative experiences are correlated with control, symmetry, order, and obsessive intrusion symptoms; however, contamination obsessions and washing compulsions are not found to be correlated with dissociative experiences. ${ }^{12,17)}$ Furthermore, studies about the relationship between OCD and dissociation show that dissociative symptoms in OCD patients make it difficult for patients to respond to both pharmacological treatment and cognitive behavioral therapy processes. ${ }^{15,18)}$

While assessing the subtypes of dissociative experiences, some researchers classify these experiences as pathological and non-pathological dissociation. ${ }^{19)}$ According to this classification, depersonalization/derealization and amnesia are accepted as pathological dissociation, absorption is characterized as non-pathological dissociation. ${ }^{19)}$ Among the studies that interpret the correlation between dissociative and obsessive-compulsive symptom subtypes; Hollander and Benzaquen ${ }^{20)}$ and Rufer et al. ${ }^{21)}$ drew attention to the relationship between pathologic dissociative experiences and OCD such as the relationship between depersonalization and obsessive-thinking tendency, amnesia and control compulsions. However, Çelikel and Beşiroğlu ${ }^{22)}$ reported that absorption, which is described as non-pathological dissociative experience, has a stronger correlation with obsessive-compulsive symptoms.

To our knowledge, in the literature; there is not a consistent conclusion about the relations of OCD with dissociation so in this study, we aimed to have a broad search about the relationship between OCD and dissociative experiences including symptom subtypes and also we wanted to interpret the effect of childhood traumatic experiences on this relationship.

\section{METHODS}

\section{Participants}

Our sample consists of 50 adult OCD patients and 50 adult healthy volunteers. A structured diagnostic interview was done with all of the participants. All patients were recruited from consecutive subjects in sequence of admission to psychiatric outpatient clinics of Bakırköy Mazhar Osman Mental Health and Neurological Diseases Education and Research Hospital in Istanbul. All of the participants in the patient group met DSM 4th edition, text revision (DSM-IV-TR) criteria for OCD and had no other 
comorbid axis 1 psychiatric disorder. This study has been approved by the local ethics comitee of Bakırkoy Mazhar Osman Mental Health and Neurological Diseases Education and Research Hospital.

\section{Instruments}

Sociodemographic and Clinical Data Collection Form

A detailed interview form prepared by researchers for evaluating the sociodemographic characteristics of the participants.

\section{Dissociative Experiences Scale (DES)}

It is a 28 itemed scale developed by Bernstein and Putnam. ${ }^{23)}$ There are three subscales that assess absorption, dissociative amnesia, and depersonalization/derealisation experiences. The validity and reliability study of Turkish version of the scale is made by Yargic et al. ${ }^{24)}$

\section{Padua Inventory (PI)}

A 60 itemed self-report scale developed by Sanavio ${ }^{25)}$ which is used to determine the severity and distribution of obsessive-compulsive symptoms in OCD patients and healthy subjects. It has 5 subscales; impulses, washing, checking, rumination, and precision. ${ }^{22)}$ The validity and reliability study for Turkish versions of original form with 60 questions and the short form with 41 questions is made by Beşiroğlu et al. ${ }^{26)}$

\section{Childhood Trauma Questionnaire (CTQ)}

A 40-item, 5-point Likert-type scale developed by Bernstein et al. ${ }^{27)}$ for screening traumatic experiences prior to the age of 18 years. The validity and reliability study for Turkish version of the scale is made by Aslan and Alparslan. ${ }^{28)}$ There are three subscales that assess physical abuse, sexual abuse and emotional neglect and abuse. ${ }^{28)}$

\section{Statistical Analysis}

Statistical analysis of the data is performed by using the IBM SPSS ver. 20.0 statistical package program (IBM Co., Armonk, NY, USA). The chi-square test is used to evaluate associations between variables. Independent $t$ test is used to assess differences between mean values of continuous variables that show normal distribution; and to assess differences between mean values of non-normal distributed continuous variables, Mann-Whitney $U$ test is used.
Spearman's correlation analysis is used for non-normal distributions in the intra-group comparisons. Linear regression model is used to assess the relationship between DES, CTQ and PI scores, for this analysis DES and CTQ are included as independent variables and PI as dependent variable. For all results $p$ value of $<0.05$ is considered to be statistically significant.

\section{RESULTS}

Fifty-two percent $(n=52)$ of the participants are female and $48 \%(n=48)$ of the participants are male. The mean age is $33.7 \pm 7.95$ years in the patient group and $33.98 \pm 8.28$ years in the control group. There is no statistically significant difference between the control and the patient group in terms of sociodemographic characteristics as age, gender, education and income level (Table 1).

In our study, it is seen that there is a statistically significant difference between all DES scores (including all subscales and total scores) of the patient and the control groups. In the patient group, mean DES total score is 20.58, while it is 4.87 in the control group (Table 2). In addition, there is also a statistically significant difference between all of the subscale and total CTQ scores of the groups except sexual abuse sub scale scores (Table 3).

When the relationship between $\mathrm{PI}$ and DES scores is examined, in the patient group, we have seen that the rumi-

Table 1. Comparison of sociodemographic characteristics of patient and control group

\begin{tabular}{lccc}
\hline \multicolumn{1}{c}{ Characteristic } & Patient & Control & $p$ value \\
\hline Gender & $24(48)$ & $24(48)$ & 1 \\
Male & $26(52)$ & $26(52)$ & \\
Female & $33.7 \pm 7.95$ & $33.98 \pm 8.28$ & 0.864 \\
Age (yr) & $(18-58)$ & $(21-58)$ & \\
& & & 0.951 \\
Education level & $12(24)$ & $10(20)$ & \\
Elementary school & $15(30)$ & $17(34)$ & \\
Secondary school & $11(22)$ & $10(20)$ & \\
High school & $12(24)$ & $13(26)$ & \\
University & $4(8)$ & $7(14)$ & \\
Income level (monthly, EUR) & $30(60)$ & \\
$<120$ & $30(60)$ & $7(14)$ & \\
$120-250$ & $11(22)$ & $6(12)$ & \\
$250-500$ & $5(10)$ & & \\
$>500$ & & & \\
\hline
\end{tabular}

Values are presented as number (\%) or mean \pm standard deviation (range).

Chi-square test is used. 
Table 2. Comparison of DES scores of patient and control group

\begin{tabular}{lccc}
\hline \multicolumn{1}{c}{ Variable } & Patient & Control & $p$ value \\
\hline Dissociative amnesia & $11.67 \pm 16.68$ & $3.44 \pm 5.09$ & 0.007 \\
Absorption & $27.25 \pm 20.59$ & $7.71 \pm 8.37$ & 0.000 \\
Depersonalization/ & $20.19 \pm 27.90$ & $1.40 \pm 3.07$ & 0.000 \\
$\quad$ derealization & & & \\
DES total & $20.58 \pm 18.67$ & $4.87 \pm 5.40$ & 0.000 \\
\hline
\end{tabular}

Values are presented as mean \pm standard deviation.

DES, Dissociative Experiences Scale.

Mann-Whitney $U$ test is used.
Table 3. Comparison of CTQ scores of patient and control group

\begin{tabular}{lccc}
\hline \multicolumn{1}{c}{ Variable } & Patient & Control & $p$ value \\
\hline Physical abuse & $27.66 \pm 9.21$ & $20.50 \pm 4.73$ & 0.000 \\
Emotional neglect and & $51.06 \pm 2.33$ & $29.46 \pm 1.58$ & 0.000 \\
$\quad$ abuse & & & \\
Sexual abuse & $6.04 \pm 2.33$ & $5.54 \pm 1.58$ & 0.073 \\
CTQ total & $84.14 \pm 24.62$ & $55.56 \pm 12.73$ & 0.000 \\
\hline
\end{tabular}

Values are presented as mean \pm standard deviation.

CTQ, Childhood Trauma Questionnaire.

Mann-Whitney $U$ test is used.

Table 4. Relationship between obsessive-compulsive symptoms and dissociative experiences in the patient group

\begin{tabular}{lccc}
\hline Variable & Dissociative amnesia & Absorption & Depersonalization/derealization \\
\hline Washing & 0.151 & 0.066 & 0.087 \\
Rumination & $0.465^{*}$ & $0.514^{*}$ & $0.582^{*}$ \\
Checking & 0.239 & 0.245 & 0.209 \\
Impulses & $0.547^{*}$ & $0.550^{*}$ & $0.705^{*}$ \\
Precision & $0.337^{\dagger}$ & $0.424^{*}$ & $0.461^{*}$ \\
PI total & $0.470^{*}$ & $0.473^{*}$ & 0.157 \\
\hline
\end{tabular}

DES, Dissociative Experiences Scale; PI, Padua Inventory.

Spearman correlation analysis is used; ${ }^{*} p<0.01,{ }^{\dagger} p<0.05$.

Table 5. Relationship between DES total and subscale scores with PI total scores in the patient group

\begin{tabular}{lcccc}
\hline PI total & $\begin{array}{c}\text { Dissociative } \\
\text { amnesia }\end{array}$ & Absorption & $\begin{array}{c}\text { Depersonalization/ } \\
\text { derealization }\end{array}$ & $\begin{array}{c}\text { DES } \\
\text { total }\end{array}$ \\
\hline$r$ value & 0.361 & 0.611 & 0.574 & 0.550 \\
$p$ value & 0.000 & 0.000 & 0.000 & 0.00 \\
\hline
\end{tabular}

DES, Dissociative Experiences Scale; PI, Padua Inventory.

Spearman correlation analysis is used.

nation subscale of $\mathrm{Pl}$ has a moderate correlation with DES amnesia ( $r=0.465, p<0.01)$, absorption $(r=0.514$, $p<0.01$ ), depersonalization/derealization $(\mathrm{r}=0.582, p$ $<0.01)$ subscales and DES total scores $(r=0.461, p$ $<0.01$ ) (Table 4). Also impulses subscale of PI has moderate correlation with DES amnesia $(r=0.547, p<0.01)$, absorption $(r=0.550, p<0.01)$ and DES total scores $(\mathrm{r}=0.547, p<0.01)$ however it has a high correlation with depersonalization/derealization $(r=0.705, p<0.01)$ subscale scores (Table 4). The precision subscale of PI has weak correlations with DES amnesia $(r=0.337, p<0.05)$, and total scores $(r=0.284, p<0.05)$ but has moderate correlations with absorption $(\mathrm{r}=0.424, p<0.01)$ and depersonalization/derealization $(\mathrm{r}=0.402, p<0.01)$ subscale scores (Table 4). When the relationship between DES scores and PI total score is evaluated, it has been seen
Table 6. Linear regression analysis of the relationship between total scores of CTQ, DES, and PI total scores in the patient group

\begin{tabular}{lclcc}
\hline Variable & $\mathrm{R}^{2}$ & \multicolumn{1}{c}{$\mathrm{B}$} & \multicolumn{1}{c}{$p$} & ANOVA \\
\hline CTQ total & 0.343 & 27.864 & $<0.0001$ & $<0.0001$ \\
Constant & & 55.14 & $<0.0001$ & \\
DES total & 0.399 & 29.983 & $<0.0001$ & $<0.0001$ \\
Constant & & 55.14 & $<0.0001$ & \\
\hline
\end{tabular}

Dependent variable, PI total.

CTQ, Childhood Trauma Questionnaire; DES, Dissociative Experiences Scale; PI, Padua Inventory.

that DES amnesia $(r=0.361, p<0.01)$, depersonalization/derealization $(r=0.574, p<0.01)$ subscales and DES total scores $(r=0.550, p<0.01)$ have moderate correlation with PI total score whereas DES absorption subscale has a stronger correlation with PI total score $(r=0.611, p<0.01)$ (Table 5).

As a result of the linear regression analysis of the relationship between the total scores of CTQ, DES and PI total scores in the patient group, we have found that DES and CTQ total scores are correlated with PI total scores independent of each other (Table 6). However, it is found that DES total scores affected the total scores of $\mathrm{PI}$ at a level of $R^{2}=0.399(p<0.01)$ while the total scores of CTQ affected the PI total scores at a level of $\mathrm{R}^{2}=0.343(p<0.01)$ 
value (Table 6).

\section{DISCUSSION}

In our study, mean DES total score in the OCD group is 20.58. This score is higher than the control group and this difference between groups is statistically significant (Table 2). In an earlier study, mean DES total scores were found to be 17.0 in eating disorders, 7.7 in pathological gambling, 11 in phobic anxiety disorders and 9.2 in neurological disorders. ${ }^{29)}$ These scores for various other neuropsychopathologies are lower than the mean DES total score of OCD patients in our research and these results suggest that there may be a closer relationship between OCD and dissociative experiences than other psychopathologies. The cognitive structure specific to OCD may lead to tendency to experience dissociative symptoms. ${ }^{30)}$ OCD is a disorder which the person tries to neutralize disturbing intrusive thoughts, such as 'suffering a loss', 'making mistakes' or 'having bad luck', with mental or behavioral compulsive actions. In OCD, patients have tendencies to make anxiety causing inferences about things that are unlikely or even impossible to happen. This tendency causes patient to be in a dilemma between knowing the truth and acting in spite of the truth. This is called 'inferential confusion' and concentration on the dilemma resulting from inferential confusion can manifest itself as dissociative experiences. ${ }^{30)}$

When we evaluate the relationship between OCD symptom severity and dissociative experiences, DES total and all subscale scores are found to be related to PI total scores (Table 4). The severity of OCD symptoms is correlated with the meaning of the content of negative intrusive thoughts, for the patient's life, because if the patient thinks the threat can cause a major damage to an important field of his/her life, he/she feels that it is necessary to show such a strong intellectual or behavioral action to protect himself/herself against the danger. If there is a strong tendency to neutralize the perception of threat, which we call compulsion, the dilemma between knowing the truth and acting in spite of the fact will be deeper for the a patient. ${ }^{30)}$

When we assess the relationship between OCD symptom subtypes and dissociative experiences in our study, obsessive impulsions and rumination symptoms are found to be more closely related to dissociative experiences than other OCD symptoms (Table 4). Watson et al." similarly reported that obsessive intrusive thoughts are more associated with dissociation than other OCD symptoms. Patient's intentional repressive attempts to remove the ego-dystonic, uncomfortable, intrusive thoughts, can conversely strengthen these thoughts, which may facilitate the transition from intentional repression to dissociation. ${ }^{31)}$ Obsessive impulses are intrusive thoughts which are about the possibility of exhibiting harmful behaviors. This thought is like one will be able to do things that he/she would never want to do as if he/she is under the influence of a foreign entity. As the imaginary self, which is able to do harmful thing, seen in obsessive impulses is apart from patient's real self, it is claimed that this is like identity dissociation peculiar to OCD. ${ }^{30)}$ We think that, there is a noteworthy similarity between dissociative identity disorder's identity alteration symptom, which is the situation of one alter handing over to another alter because of ego-dystonic thoughts or feelings, and OCD patient's intrusive thoughts which is about possessing a 'potential self' which can do harmful things, that the person would never want to do. ${ }^{6)}$

In our study, when we examine the relationship between OCD symptom severity and dissociative experiences in the patient group, we found that the DES subscale, which has the strongest correlation with the PI total score, is the absorption subscale (Table 5). Absorption can be defined as a state of consciousness that perceptual, memorial and ideational attention is directed to only one aspect of cognition. Another definition of absorption is doing an intellectual or behavioral act so intensely that nothing else that is happening around can be noticed. ${ }^{31)}$ Absorption, by its psychoanalytic definition, is closely related to isolation defense mechanism of ego which is thought to be effective in the development of OCD. OCD patients report that when they are doing rituals related to the disorder, they feel like being in a balloon, which is broken off from the real world. ${ }^{30)}$ In a study in which the effects of OCD patients' dissociative experiences on cognitive behavioral therapy processes, are evaluated, it has been reported that, patients with high absorbance capacity during the exposure process of the therapy, show poor habituation to the action or state to be confronted due to dissociative experiences. ${ }^{15)}$ Researchers of the study have commented that as the emotional arousal processes are damaged in patients due to absorption during the exposure sessions, patients do not get adequate re- 
sponse to the therapy. ${ }^{15)}$

Dissociative disorders have the strongest etiological association with childhood traumatic experiences among all psychiatric pathologies. ${ }^{32,33)}$ Therefore, in our study, while the relationship between OCD symptoms and dissociative experiences is being examined, possible effects of childhood traumatic experiences on this relationship are also investigated in the patient group. Results of the linear regression analysis showed that the association between OCD symptoms and dissociative experiences is independent of childhood traumatic experiences and also we found that the association between OCD symptoms and dissociative experiences is stronger than the association between OCD and childhood traumatic experiences (Table 6). Childhood traumatic experiences may increase the susceptibility of a person to dissociation. However rather than the pathological dissociation seen as a result of trauma, the dissociative experiences observed in OCD patients are more likely to be related with the common cognitive issues, that is seen both in OCD and dissociative disorders, such as difficulty in reconciliation pre-existing schemes with new information coming from outside and difficulty in adaptation to new events. ${ }^{34)}$

In conclusion, results of our study show that, dissociative experiences can be seen more frequently in OCD patients than healthy population. Absorption, which is considered as non-pathological dissociation, has a stronger association with OCD symptoms than the other dissociative experiences. The relationship between OCD and dissociation is independent of childhood traumatic experiences and this relationship is stronger than the one between childhood traumatic experiences and OCD.

The limitation of our study is its small sample size, in a larger sample, the significance of statistical meaning of indications' distribution and relationship with each other will be higher.

\section{REFERENCES}

1. American Psychiatric Association. Diagnostic and statistical manual of mental disorders. 5th ed. Köroğ/u E, translator and editor. Ankara:Hekimler Yayın Birliği:2013.

2. Belli H. Dissociative symptoms and dissociative disorders comorbidity in obsessive compulsive disorder: Symptom screening, diagnostic tools and reflections on treatment. World I Clin Cases 2014;2:327-331.

3. Dell PF, O'Neil JA. Dissociation and dissociative disorders: DSM V and beyond. New York:Routledge;2009.
4. Şar V. The many faces of dissociation: opportunities for innovative research in psychiatry. Clin Psychopharmacol Neurosci 2014;12:171-179.

5. Spitzer C, Spelsberg B, Grabe HJ, Mundt B, Freyberger HJ. Dissociative experiences and psychopathology in conversion disorders. J Psychosom Res 1999;46:291-294.

6. Pica M, Beere D, Maurer L. The overlap between dissociative and obsessive compulsive disorders: a theoretical link. Dissociation 1997:10:38-43.

7. Watson D, Wu KD, Cutshall C. Symptom subtypes of obsessive-compulsive disorder and their relation to dissociation. J Anxiety Disord 2004; 18:435-458.

8. Topçuoğlu V. [Psychoanalytic views on obsessive-compulsive disorder]. J Clin Psy 2003:6:46-50. Turkish.

9. Lochner C, Seedat S, Hemmings SM, Kinnear CJ, Corfield VA, Niehaus DJ, et al. Dissociative experiences in obsessive-compulsive disorder and trichotillomania: clinical and genetic findings. Compr Psychiatry 2004;45:384-391.

10. Merckelbach H, Wessel I. Memory for actions and dissociation in obsessive-compulsive disorder. J Nerv Ment Dis 2000;188:846-848.

11. Prasko J, Raszka M, Diveky T, Grambal A, Kamaradova D, Koprivova J, et al. Obsessive compulsive disorder and dissociation - comparison with healthy controls. Biomed Pap Med Fac Univ Palacky Olomouc Czech Repub 2010;154: 179-183.

12. Goff DC, Olin JA, Jenike MA, Baer L, Buttolph ML. Dissociative symptoms in patients with obsessive-compulsive disorder. J Nerv Ment Dis 1992;180:332-337.

13. Belli H, Ural C, Vardar MK, Yesilyurt S, Oncu F. Dissociative symptoms and dissociative disorder comorbidity in patients with obsessive-compulsive disorder. Compr Psychiatry 2012;53. 975-980.

14. Hodgson RJ, Rachman S. Obsessional-compulsive complaints. Behav Res Ther 1977;15:389-395.

15. Rufer M, Held D, Cremer J, Fricke S, Moritz S, Peter $\mathrm{H}$, et al. Dissociation as a predictor of cognitive behavior therapy outcome in patients with obsessive-compulsive disorder. Psychother Psychosom 2006; 75:40-46.

16. Raszka M, Prasko J, Koprivová J, Novák T, Adamcová K. Psychological dissociation in obsessive-compulsive disorder is associated with anxiety level but not with severity of obsessive-compulsive symptoms. Neuro Endocrinol Lett 2009; 30:624-628.

17. Grabe HJ, Goldschmidt F, Lehmkuhl L, Gänsicke M, Spitzer C, Freyberger HJ. Dissociative symptoms in obsessive-compulsive dimensions. Psychopathology 1999;32:319-324.

18. Semiz UB, Inanc L, Bezgin CH. Are trauma and dissociation related to treatment resistance in patients with obsessive-compulsive disorder? Soc Psychiatry Psychiatr Epidemiol 2014; 49:1287-1296.

19. Maaranen P, Tanskanen A, Honkalampi K, Haatainen K, Hintikka J, Viinamäki H. Factors associated with pathological 
dissociation in the general population. Aust N Z J Psychiatry 2005; 39:387-394.

20. Hollander E, Benzaquen SD. The obsessive-compulsive spectrum disorders. Int Rev Psychiatry 1997:9:99-110.

21. Rufer M, Fricke S, Held D, Cremer J, Hand I. Dissociation and symptom dimensions of obsessive-compulsive disorder. A replication study. Eur Arch Psychiatry Clin Neurosci 2006; 256:146-150.

22. Çelikel H, Beşiroğlu L. Childhood traumatic experiences, dissociation and obsessive-compulsive symptoms in non-clinical samples. Anadolu Psikiyatri Derg 2008:9:75-83.

23. Bernstein EM, Putnam FW. Development, reliability, and validity of a dissociation scale. J Nerv Ment Dis 1986;174:727735.

24. Yargic LI, Tutkun H, Sar V. The reliability and validity of the Turkish version of the dissociative experiences scale. Dissociation 1995:8:10-13.

25. Sanavio E. Obsessions and compulsions: the Padua Inventory. Behav Res Ther 1988;26:169-177.

26. Beşiroğlu L, Yücel Ağargün M, Boysan M, Eryonucu B, Güleç $\mathrm{M}$, et al. [The assessment of obsessive-compulsive symptoms. the reliability and validity of the Padua inventory in a Turkish population]. Turk Psikiyatri Derg 2005;16:179-189. Turkish.

27. Bernstein DP, Fink L, Handelsman L, Foote J, Lovejoy M, Wenzel K, et al. Initial reliability and validity of a new retrospective measure of child abuse and neglect. Am J Psychiatry
1994;151:1132-1136.

28. Aslan SH, Alparslan ZN. The reliability, validity and factor structure of the childhood trauma questionnaire among a group of university students. Turk Psikiyatri Derg 1999:10: 275-285.

29. Putnam FW, Carlson EB, Ross CA, Anderson G, Clark P, Torem $\mathrm{M}$, et al. Patterns of dissociation in clinical and nonclinical samples. J Nerv Ment Dis 1996;184:673-679.

30. O'Connor K, Aardema F. Living in a bubble: dissociation, relational consciousness and obsessive compulsive disorder. J Conscious Stud 2012:19:216-246.

31. Yücel Ağargün M, Beşiroğlu L, Kemal Kiran U, Kara H, Akil Ozer O. [The reliability and validity of the White Bear Suppression Inventory]. Turk Psikiyatri Derg 2004;15:282290. Turkish.

32. Butler LD, Duran RE, Jasiukaitis P, Koopman C, Spiegel D. Hypnotizability and traumatic experience: a diathesis-stress model of dissociative symptomatology. Am / Psychiatry 1996;153(7 Suppl):42-63.

33. Irwin HJ. Pathological and nonpathological dissociation: the relevance of childhood trauma. J Psychol 1999;133:157-164.

34. Selvi Y, Besiroglu L, Aydin A, Gulec M, Atli A, Boysan M, et al. Relations between childhood traumatic experiences, dissociation, and cognitive models in obsessive compulsive disorder. Int J Psychiatry Clin Pract 2012;16:53-59. 